\title{
Consumo informativo y competencias digitales de estudiantes de periodismo de Colombia, Perú y Venezuela
}

\author{
Consumption of information and digital competencies of journalism \\ students from Colombia, Peru and Venezuela
}

\author{
Luis M. Romero-Rodríguez / lmiguel.rrodriguez@alu.uhu.es \\ Ignacio Aguaded / ignacio@aguaded.es \\ Universidad de Huelva, España
}

\begin{abstract}
This paper proposes to examine the information consumption habits emerging in journalism students in Colombia, Peru and Venezuela, in particular the trend of infoxication and information overload in their communication ecosystem and also to analyze the medialiteracy skills acquired over their training. The methodology focused on a digital selfadministered quantitative questionnaire, applied to 1,603 third-year students of journalism at universities in Medellin, Lima and Caracas. Key findings are intensive use of Internet and social media that exceeds 5 hours a day, with especial attention to the fact that most of the content received through these networks is pseudo-information and stressing that media literacy training for informative consumption is preeminently self-taught.
\end{abstract}

Key words: infoxication, information overload, data smog, information consumption habits, media literacy.

Resumen: El objeto del presente artículo es profundizar en los hábitos de consumo informativo que se perfilan en estudiantes del grado de comunicación en Colombia, Perú y Venezuela, en particular sobre la tendencia a la infoxicación y sobresaturación informativa de su propio ecosistema comunicativo, así como indagar sobre las competencias comunicativas que han obtenido en su formación. La metodología se centró en un cuestionario autoadministrado digital de carácter cuantitativo, aplicado a 1.603 estudiantes de tercer año en universidades privadas de Medellín, Lima y Caracas. Entre las principales conclusiones se destaca un intensivo consumo de internet y redes sociales que supera las cinco horas diarias, con especial atención a que la mayor parte de los contenidos recibidos a través de sus redes son pseudoinformaciones y que la formación en competencias mediáticas para el consumo informativo se hace preminentemente de manera autodidacta.

Palabras clave: infoxicación, sobresaturación informativa, infobesidad, hábitos de consumo informativo, competencias mediáticas. 


\section{Introducción}

La disminución de los costos de teléfonos inteligentes y tabletas y la masificación significativa del uso de internet en Iberoamérica han sido factores determinantes para la creación y modificación de hábitos de consumo informativo tendientes a la infoxicación (Shenk, 2003: 396-397; Cornella, 2010; Aguaded y Romero-Rodríguez, 2015: 47), entendiendo ésta como un exceso de consumo de información innecesaria para la toma de decisiones -mayoritariamente contenidos de entretenimiento-, ergo sobresaturación de la capacidad cognitiva de un individuo que acarrea distracción de los asuntos de importancia y su propia alienación racional (Dias, 2014; Romero-Rodríguez, 2014: 33-48).

En el caso español, la universalización del acceso a la red en jóvenes de entre 16 a 24 años llega al 97.4\% (INE, 2013), mientras que la penetración total del uso de internet en Colombia (59.5\%), Perú (36.5\%) y Venezuela $(41.0 \%)$ es mayoritariamente representada por jovenes de edades comprendidas entre 15 y 23 años (Internet World Stats, 2012). El acceso permanente y ubicuo que permiten las plataformas móviles de internet chats, redes sociales y aplicaciones- pudieran estar generando una sobresaturación cognitiva y distracción inmanente por la ausencia de infodietas y educación en competencias mediáticas, informacionales y digitales, incluso en futuros periodistas, sirviendo como caldo de cultivo de una desinformación estructural en la sociedad.

Las estadísticas recientes sobre el uso de las tecnologías de la información y la comunicación (TIC) demuestran, en un estudio realizado a nivel mundial en 21 naciones, que la población se ha integrado al uso de internet, en particular al uso de redes sociales por medio de los teléfonos inteligentes, constituyéndose estas herramientas tecnológicas en las más populares y utilizadas entre los sujetos menores de 30 años y con educación universitaria (Pew Research Center, 2014).

No en vano la juventud ha tenido una especial atención en la literatura académica en torno a las TIC (Tapscott, 2009). Los jovenes actualmente interactúan con las redes sociales más que en cualquier otro grupo social (Cabalin, 2014), lo cual ha generado un sinfín de debates entre entusiastas y escépticos -en palabras de Eco (1964), Apocalípticos e Integrados- sobre los beneficios y perjuicios que estos espacios colaborativos generan.

Como principales provechos de los hábitos de interacción de los jóvenes en redes sociales se podrían enumerar el "activismo de una generación 
conectada”, más vinculada con temas políticos y sociales (Herrera, 2012), un sistema de producción y consumo (prosumo) independiente y alejado de "mecanismos de manipulación simbólica" (Castells, 2012: 5), un potente instrumento para el aprendizaje y la formación intelectual y profesional (Rial et al., 2014); mientras que, por el contrario, aparecen problemas, más frecuentes en la población joven, como la adicción a estar conectados y los efectos de la "hiperconexión", que pueden generar estrés, aislamiento social, conflictos familiares, descenso en el rendimiento académico, degradación del lenguaje, potenciar conductas individualistas y suplantación de identidades (Shapira et al., 2003; Echeburúa y de Corral, 2010; Caldevilla, 2010; Lee y Stapinski, 2012), siendo las redes sociales y los videojuegos online los que más adictos están generando (Lam et al., 2009).

Este artículo tiene como principal objetivo analizar los hábitos de consumo informativo y comportamientos frente a la recepción del contenido proveniente de internet de estudiantes del tercer año de Periodismo de universidades privadas en Medellín, Lima y Caracas. Más concretamente se incorporó una comparativa de las tipologías de acceso y contenido recibido, tanto entre las entidades geográficas referidas, como de los grupos etarios, con el fin de identificar cuáles grupos son más propensos a la infoxicación.

En segundo lugar, se intentará verificar la calidad de los contenidos a los que los prospectivos periodistas acceden en función de la utilidad de las informaciones, en razón de su provecho académico, profesional o para el proceso de toma de decisiones, y finalmente profundizará en las competencias mediáticas de la muestra analizada y su percepción acerca de la importancia de la formación en materia educomunicativa (media literacy).

Se considera pertinente realizar el presente estudio a estudiantes de Periodismo, teniendo en consideración que son sujetos en fase de capacitación para el ejercicio de esta profesión, cuyo fundamento es el manejo responsable de los contenidos informativos, en el entendido de que serán éstos los que a futuro fungirán como recodificadores de acontecimientos y creadores del discurso mediático. De esta forma se considera que es un público que debe tener una formación académica encaminada a la selección y filtrado de informaciones útiles, y que debe conocer y saber diferenciar, mejor que otros grupos que comparten sus rangos etarios comunes, la dinámica informativa y de pseudoinformaciones en internet y sus múltiples plataformas.

El presente estudio se realiza tomando como base metodológica las investigaciones de Livingstone (2008), Livingston y Helsper (2010), Livingstone y Brake (2010), Livingstone et al. (2011), Valcke et al. (2011) y el más 
novedoso estudio en el contexto español de García, López-de-Ayala y García (2013); trabajos que si bien toman como objeto la interrelación entre menores e internet en razón a los contenidos a los que pueden estar sometidos, se adaptarán en esta investigación a la población referida ut supra.

Asimismo, se toma como referencia el trabajo de Marín-Díaz, Sampedro-Requena y Muñoz-González (2015) donde se analiza la adicción de los jóvenes universitarios a las redes sociales y los trabajos presentados por Gisbert y Esteve (2011) y Gallardo (2012), que examinan el estado de la cuestión acerca de los niveles de afectación de las tecnologías en estudiantes universitarios y sus competencias digitales, a la luz del entendimiento de que las nuevas generaciones han cambiado radicalmente la manera de interrelacionarse e informarse por la irrupción de las nuevas tecnologías.

\section{Infoxicación e infobesidad: estado de la cuestión}

El concepto de infoxicación e infobesidad se ha estado analizando a la luz del acceso informativo omnipresente que la sociedad moderna comienza a tener gracias a las TIC, las cuales permiten con relativa facilidad manejar y ampliar sus relaciones sociales y el acceso infinito a la información de la red (BenitoRuiz, 2009; Cornella, 2010; Dias, 2014), dando como resultado frecuente una sobresaturación cognitiva y la reducción de la capacidad de comprensión, análisis y apreciación de dicha información en el proceso de toma de decisiones (Gross, 1964; Shenk, 2003; Speier et al., 1999).

Sin embargo, aún cuando la infoxicación comienza a ser objeto de estudio con gran interés científico, a consecuencia de la masificación que viene ocurriendo con el acceso a internet, Jacoby, Speller y Kohn (1974) y Jacoby $(1977,1984)$ ya advertían que el consumo informativo no moderado puede tener consecuencias disfuncionales en los procesos cognitivos y la toma de decisiones. Incluso en 1970, el escritor futurista Alvin Toffler (1970: 171173) acuñaba el término information overload para referirse a la sobreestimulación sensorial por la cual percibimos la construcción de la realidad y que afecta nuestra habilidad de pensar, pues irrumpe el flujo continuo de la información que necesitamos.

El modelo de producción informativa actual, caracterizado por una sociedad ávida del prosumo, la globalización de sus intereses y comunicaciones, la multiplicidad de plataformas de conexión y el incremento de la necesidad de estar "conectada", van creando un caldo de cultivo de una sociedad sobresaturada y distraída en la cual la sobreexposición informativa se constituye 
como el propio flujo sanguíneo de la civilización (Shenk, 2003; Gitlin, 2005; Bray, 2008; Gleick, 2011; Andrejevic, 2013).

De hecho, para finales de 2013 se reportaban por minuto 204 millones de correos electrónicos, 20 horas de videos en YouTube, 2 millones de búsquedas en el motor Google, 73 compras electrónicas en Amazon y 850 mil interacciones en las redes sociales (Nielsen, 2014), lo cual hace imposible que el sujeto pueda recolectar siquiera un porcentaje significativo de toda la información sobre todos los acontecimientos que transcurren durante su vida, entendiendo que nuestra evolución cerebral y cognitiva ha permanecido inerte por más de cincuenta mil años, aun cuando la oferta de información mantiene un exponencial crescendo (Shenk, 2003; Cortés, 2006).

Este escenario genera que los individuos se adapten a la sobrecarga de estímulos al dedicarle menor tiempo a cada input -ingreso informativo-, bloqueando la recepción de otros inputs por efecto de la "escotomización voluntaria" e instalando filtros para mantener la cantidad de datos a niveles que puedan manejar (Milgram, 2010), lo cual crea una disonancia inherente al propio proceso comunicativo, donde gran parte de la carga informativa es automáticamente rechazada por el exceso de la información que ya se tiene, pudiendo caer el receptor en un vicio de preferencias en contenido pseudoinformativo, rechazando aquellos mensajes que sean más idóneos para la representación de la realidad del conocimiento por su utilidad en la toma de decisiones.

Esto significa que los sujetos rechazan gran parte de la información que reciben por la incapacidad de procesarla y mantenerla en resguardo, por lo tanto el problema reside en la capacidad del individuo para catalogar, filtrar y conservar la información útil y desechar aquella que no tenga valor en términos de utilidad.

\section{Las barreras de asimilación cognitiva y la pseudoinformación}

Para un efectivo proceso de toma de decisiones es necesaria una cierta cantidad y calidad de información, pero el exceso de ésta conllevaría gradualmente a un decrecimiento proporcional de la capacidad cognitiva, dependiente de las habilidades de procesamiento y competencias comunicativas de su filtrado. Por esta razón, no necesariamente quien recibe mayor cantidad de información es quien está mejor informado, sino aquel que sabe filtrar la información que le es útil y desechar la que no. 
Así, cuando la cantidad de información recibida $Q_{i}$ incrementa, el límite teórico de habilidad de filtrado del sujeto $\left(R_{0}\right)$ aumenta proporcionalmente a su habilidad real de procesamiento (SS). Sin embargo, a mayor cantidad de información, se expande más la brecha diferencial entre la habilidad real (SS) y su límite teórico de filtrado $\left(R_{0}\right)$, expresados en una línea curva debido al decrecimiento de calidad de la información por efecto de la cantidad - sobresaturación- (Stewart et al., 1992: 131).

La hipótesis anterior asume que mientras la cantidad de información recibida $\left(Q_{i}\right)$ sea menor o igual que la capacidad de asimilación cognitiva $\left(C_{A}\right)$, se traduce en la habilidad real (SS) -porque el sujeto puede asumir esa cantidad de información-, en el entendido de que la habilidad real (SS) es aquella que se adquiere por la cantidad de inputs asimilados cognitivamente para la toma de decisiones o recodificación de información. Por eso se entendería a la sobresaturación e infoxicación $\left(S_{I}\right)$ como el exceso de cantidad de información $\left(Q_{i}\right)$ mucho mayor que la capacidad de asimilación cognitiva $\left(C_{A}\right)$ (Romero-Rodríguez, 2014): $S_{I}=Q_{i}<C_{A}$

El problema se suscita en el proceso de selección de las informaciones, pues si bien la infoxicación ocasiona una ruptura del proceso cognitivo generando disonancia y ruido psicológico, tanto por exceso como por inutilidad informativa, un incorrecto hábito de consumo y la insuficiencia de competencias comunicativas y digitales para la correcta selección y filtrado también generaría que el receptor se haga con pseudoinformaciones, y lo que es peor, que sea factor multiplicador y redifusor de dichos contenidos a través de las multidiversas plataformas que existen en la red.

De esta manera, la sobrecarga informativa y el acceso permanente y no racional a internet podría generar desinformación estructural, pues, por un lado, las acciones multitarea (multitasking) ocasionan distracción no-volitiva del sujeto frente a las actividades que comúnmente desempeñan; y, por otro, el grueso de los datos a los cuales se acceden no necesariamente son útiles para el desarrollo personal y profesional del receptor, mientras que los propios filtros cognitivos pueden rechazar informaciones útiles, confundiendo al sujeto y generando un caldo de cultivo idóneo para la desinformación (Romero-Rodríguez, 2012; 2014).

Por ello, el superávit de información exige el discernimiento necesario para seleccionar los contenidos más provechosos y dedicarle el tiempo pertinente (Serrano-Puche, 2014), aunque merece la pena constatar que en el contexto de la sobrecarga informativa los receptores llegan a confiar más en sus contactos de las redes sociales como filtros primarios (Rainie y Well- 
man, 2012), pudiendo estarse transformando los sujetos en "islas encerradas en burbujas de convicciones" (Doval, 2012), lo cual en definitiva ocasiona la parcelación perceptiva para la creación de realidades dependiendo de la otredad, privándole al receptor de una visión interpretativa más holística e integradora de los acontecimientos (Pariser, 2011).

\section{La competencia digital y la infodieta}

La competencia digital se define como un conjunto de habilidades, capacidades, destrezas y conocimientos para el uso y consumo de información en internet, que en contrapartida mantiene una imperiosa necesidad del sujeto de estar conectado (Gisbert y Esteve, 2011). Las nuevas generaciones, las cuales han tenido diversos adjetivos como "Millenians" (Howe y Strauss, 1991; Lancaster y Stillman, 2002; Martin y Tulgan, 2002; Oblinger y Oblinger, 2005), "Generación Digital" (Tapscott, 2009), "Nativos digitales" (Prensky, 2001) o "i-Generation” (Rosen et al., 2010), se distinguen, según estos autores, por una marcada alfabetización digital, su sentido de la inmediatez, su carácter social y su tendencia multitarea; aunque otros autores como White (2010) y Corrin et al. (2010) discuten que la competencia digital no es relativa o proporcional a un grupo etario o a características generacionales, sino por la aproximación que éstos hacen a las tecnologías, por lo tanto no puede asegurarse que existan dos generaciones distintas - nativos y no nativos digitales-, sino hábitos de acercamiento distintos frente al entorno digital.

Independientemente de lo anterior, las generaciones actuales tienen mayor facilidad a su exposición a las multipantallas y tendencia de hiperconexión prosumidora (Morduchowicz, 2008; Sabada y Bringué, 2009; Aguaded y Sandoval, 2011; Sandoval y Aguaded, 2012), que requieren formación para que sus interacciones con la red sean racionales y responsables, tanto en el análisis y crítica de los mensajes recibidos, como también en sus roles de productores y distribuidores de contenidos a través de sus nodos sociales-digitales.

La educación en medios toma un papel vital para asumir la necesidad que imponen las competencias comunicativas en la formulación de dietas digitales, no sólo por la demasía de contenidos, sino también por una imperante cultura de la velocidad y un relativo triunfo de lo trivial y superficial sobre lo importante, sobre todo en el contexto digital. 
Por ello, una correcta dieta informativa debe comprender que la sobrecarga de inputs afecta la productividad (Hurst, 2007; Serrano-Puche, 2014) y la memoria (Klingberg, 2009; Niada, 2010), siendo la capacidad multitasking un mito, pues la concentración es indivisible (Crenshaw, 2008), lo cual ocasiona distracción objetiva (Romero-Rodríguez, 2014). Así, se debe atender al "principio de relevancia" (Lucchetti, 2010), como habilidad del sujeto a escoger la información útil y desechar la que no, enfocándose en dirigir su capacidad receptiva a las fuentes primarias de la información y no al prosumo de opiniones tergiversadas, memes y contenidos virales (Johnson, 2012; Rodríguez, 2013), al igual que obtener competencias a través de la educación en medios para avivar el pensamiento estadístico, masa crítica, habilidades de búsqueda y de filtrado informativo (Reig y Vílchez, 2013; Serrano-Puche, 2014).

\section{Método}

En el presente esfuerzo investigador se ha optado por realizar una encuesta de carácter cuantitativa a estudiantes del tercer año del grado de Ciencias de la Información, Periodismo, Comunicación Social o afines en universidades privadas de Medellín (Colombia), Lima (Perú) y Caracas (Venezuela), con el objeto de conocer sus hábitos de consumo informativo en internet, valorar la calidad de las informaciones a las que generalmente acceden y evaluar su formación en competencias comunicativas para el establecimiento de infodietas que prevengan la infoxicación, infobesidad y el uso de pseudoinformaciones.

Como hipótesis de partida (H1), se plantea que los estudiantes mantienen un hábito de consumo informativo desmesurado, lo cual genera las condiciones idóneas para su infoxicación. La segunda hipótesis (H2) afirma que el grueso de los datos a los que acceden los prospectivos periodistas tienen un alto contenido pseudoinformativo o trivial, no vinculado con su desarrollo personal o profesional ni útil para sus procesos de tomas de decisiones. Por último, la tercera hipótesis $(\mathrm{H} 3)$ asevera que no existen planes o programas de formación en competencias comunicativas a edad temprana que fijen una infodieta y hábitos de consumo responsable de los medios de comunicación e internet.

\section{Estrategias metodológicas}

Se realizó un estudio cuantitativo procedente de una encuesta estadística no representativa aplicada de forma autoadministrada a estudiantes del tercer 
año (cuarto y quinto semestre) de la carrera de Ciencias de la Comunicación, Periodismo, Comunicación Social o afines de universidades en Medellín (Colombia), Lima (Perú) y Caracas (Venezuela), durante el periodo lectivo 2014/2015, ejecutada entre los meses de septiembre y octubre de 2014 . Esta muestra con selección no-aleatoria de la totalidad de 1.603 estudiantes universitarios, con edades entre 16 y 30 años $\left(M_{\mathrm{EDAD}}=21,57\right)$ de los que 989 $(61,69 \%)$ eran mujeres y $614(38,30 \%)$ eran hombres (véase Tabla $\left.1^{1}\right)$.

Dicha encuesta se ejecutó a través de la herramienta Typeform, contando con el apoyo de docentes de distintas universidades de las señaladas ciudades para promover su cumplimento e incluía preguntas dicotómicas, escala de Likert y selección múltiple. El cuestionario, con 18 preguntas, ha seguido una secuencia lógica que comenzaba con breves preguntas sociodemográficas - país, universidad, edad y género-, continuando con cuestiones relativas a las hipótesis planteadas. Se escogió la aplicación del cuestionario a través de internet debido a su naturaleza de rapidez en la recogida de información, el bajo coste de su aplicación y la separación entre encuestador y el encuestado (Díaz-de-Rada, 2012), características que se adaptaban perfectamente a los objetivos y la línea de este estudio. Asimismo, se realizaron las encuestas en universidades privadas ya que no se pudo obtener las autorizaciones necesarias para la ejecución de los instrumentos en sus pares públicas.

Posteriormente, para el análisis de los resultados se utilizó la versión 18 del programa estadístico IBM-SPSS ${ }^{\circledast}$ mediante el comando "Tablas personalizadas" que permite generar tablas de contingencia, incluyendo más de dos entradas de variables, y a la vez controlando los efectos de terceras variables que se interrelacionan con las variables dependientes (país, género y edad). El nivel de validez estadística que nos indicará el no-azar de las diferencias detectadas será $X^{2}<0.05$. La muestra efectiva total recogida fue de 1.603 estudiantes, estratificados de la manera que indica la Tabla 1.

\section{Análisis y resultados}

En primer lugar se describen los hábitos de consumo informativo de los encuestados en función al tiempo que dedican a navegar por internet al día, las actividades que realizan paralelamente al acceso a la red y la cantidad de ventanas, pestañas o aplicaciones que mantienen en simultáneo - multitasking-. Los siguientes tres subapartados analizan: 1) la completitud de su revisión de

1 Todas las tablas y la figura se encuentran en el Anexo, al final del presente artículo (Nota del Editor). 
las informaciones en páginas web y redes sociales; 2) los tipos de información o pseudoinformación más comúnmente recibida y su hábito de consumo; 3) la percepción de los encuestados sobre la pertinencia e idoneidad de adquisición de competencias comunicativas para fijar infodietas y hábitos de consumo informativo responsables.

\section{Hábitos de consumo informativo en la red}

El primer factor estudiado es el tiempo por jornada diaria y la actividad que llevan a cabo los estudiantes referidos en la red. Entre cinco y ocho horas al día es el tiempo que aseguran dedicar a navegar por internet el 67,2\% de la muestra, alcanzando 74,7\% si incluimos aquellos que dicen navegar más de ocho horas al día. Sobre este resultado, las mujeres son quienes más tiempo navegan por internet, con un $81,3 \%$ que accede durante más de cinco horas al día; mientras que en el grupo etario de 20-23 años, 77,2\% afirma dedicarse a esta actividad entre cinco y ocho horas al día.

En relación con el hábito de consumo de internet por país, Venezuela lidera el tiempo de acceso por jornada diaria con $84,5 \%$ que se conecta durante más de cinco horas al día, seguido por Perú con $81,1 \%$ y Colombia con $77,8 \%$, ambos en ese mismo intervalo de tiempo.

El segundo factor analizado se refiere a la tendencia de operación multitarea - multitasking- que comparten las actividades diarias en paralelo con el acceso a internet. El 68,2\% de los encuestados respondió que generalmente navega por internet a la vez que realiza cualquier actividad diaria como asistir a clases, en medio de una conversación, a la hora de comer o en todo momento; $21,6 \%$ aseveró que en cualquier momento libre, es decir, cuando no hace ninguna otra tarea, mientras que $10,2 \%$ dijo que se conectaba solamente cuando existía una red WiFi disponible o que rara vez se conectaba a internet.

Para evaluar la actividad multitarea también se tomó en consideración valorar la tendencia a las múltiples ventanas, pestañas o aplicaciones operando en segundo plano en una misma conexión. De esta manera, el 58,2\% de la muestra estudiada informó que comunmente mantenía más de seis pestañas, ventanas o aplicaciones abiertas en paralelo; mientras 34,6\% opera simultáneamente con más de tres pero menos de seis pestañas, ventanas o aplicaciones; en tanto, sólo el 7,2\% restante accede a internet utilizando menos de tres. En relación con estos datos, las razones de la decisión de abrir una nueva pestaña, ventana o aplicación son: continuar la lectura posteriormente, aun- 
que afirman nunca proseguirla $(67,2 \%)$, rapidez en el acceso a la información $(28,6 \%)$ y continuar a posteriori la lectura, lo cual afirman hacer o señalan que nunca abren una nueva ventana sin cerrar la anterior ( $4,2 \%)$.

\section{Completitud de revisión de informaciones en la red}

Un primer dato interesante se refiere a los hábitos de lectura de las informaciones de las páginas web y redes sociales que los prospectos periodistas visitan: el 86,2\% asegura que cuando navega en un sitio web no suele leerlo entero; es el grupo etario 16-19 años el que en 98,6\% afirma su incompletitud de revisión de la totalidad de un espacio web.

Respecto a las informaciones que aparecen resumidas en las redes sociales y tienen hipervínculos o enlaces externos para acceder a la totalidad de la información, 72\% de los encuestados asevera que sólo lee el resumen o el extracto de la noticia en su timeline (Twitter) o historial de inicio (Facebook), antes de compartirlo, comentar la nota, darle a la opción "Me gusta" (Facebook) o a "Favoritos" (Twitter); en tanto, sólo el 28\% restante confirma la lectura íntegra de la información antes de optar por difundirla a sus contactos.

En relación con la redifusión (compartir o retweet) de información, es el grupo etario más joven (16-19 años) el que confirma hacerlo con mayor frecuencia sin antes haberla leído completamente con $96,3 \%$ de respuestas positivas.

Respecto a los diferentes grupos geográficos, no se entreven diferencias muy marcadas en cuanto a los hábitos de completitud informativa, siendo la muestra venezolana la que refleja mayor tendencia a no leer la totalidad de la información de una página web (87\%), seguido por los prospectivos periodistas peruanos con $86,2 \%$ y sus pares colombianos con $85,5 \%$.

\section{Tipología y hábitos de consumo de información}

En correspondencia al cúmulo informativo o pseudoinformativo que reciben en sus redes sociales (Facebook y Twitter), los estudiantes de periodismo analizados en el presente estudio atestiguan que $58,6 \%$ se trata de listados e información viral con poco contenido útil para sus decisiones y formación profesional; $21,1 \%$ son videos musicales y/o virales; $13,4 \%$ son noticias e información útil, y el restante $6,9 \%$ frases célebres y otro tipo de contenidos, lo cual deja en meridiana evidencia que la información recibida en el ecosistema 
de las redes sociales es mayoritariamente pseudoinformación en términos de utilidad.

Las mayores diferencias entre los datos referidos se reflejan con mayor frecuencia en los grupos por edades: el etario de 20-23 años es el que más pseudocontenido informativo recibe, con 96,3\%; mientras que en los mayores de 28 años disminuye esta cifra hasta 70\% (véase Tabla 2). En el caso de la estratificación de la datos por sexo o área geográfica, no surgen grandes divergencias diferenciales. De hecho, la prueba de Chi-Cuadrado de Pearson, tomando como variable independiente las edades, nos arroja un valor de 83,948(a) con una frecuencia esperada inferior a 5; en tanto, la frecuencia mínima esperada es 1,03 (véase Tabla 3), lo cual pone de manifiesto la existencia de diferencias estadísticamente significativas entre los distintos grupos etarios.

Son los prospectivos periodistas mayores de 28 años quienes reciben mayor información útil para su desarrollo personal, profesional y toma de decisiones (30\%), seguido por el grupo 24-27 (10,3\%); mientras que en las edades comprendidas entre 16 a 23 años suman $13,2 \%$, totalizando esta tipología de contenidos útiles sólo 13,4\% del promedio de recepción informativo en sus redes sociales (véase Figura 1).

El cuestionario incluía también cuatro unidades informativas con diferentes niveles de utilidad, dándole la oportunidad al encuestado de decidir sobre cuál de ellas ahondaría. Así, la muestra analizada asevera que profundizaría más en un enlace que muestra fotos y videos de una pelea entre el actor Orlando Bloom y Justin Bieber $(41,2 \%)$ o que el primer ministro canadiense deja de seguir a Homero Simpson en Twitter (31,1\%); mientras, 15,3\% de los estudiantes asegura que accedería con prioridad a una información sobre su carrera profesional y $12,4 \%$ a un trabajo de investigación sobre una posible solución del conflicto del Oriente Medio.

Al ser cuestionados acerca de las posibilidades de obtener información errónea o contenidos desinformativos en internet frente a los que divulgan los medios tradicionales - prensa, radio y televisión-, el 52,4\% de los encuestados refieren que en internet se encuentra exactamente la misma información que en los medios tradicionales; 38,6\% afirma que es más probable desinformarse a través de contenidos de internet; por su parte, sólo el $9 \%$ aduce que es más probable encontrar información errónea o contenidos desinformativos en los medios tradicionales. 
Luis M. Romero-Rodríguez e Ignacio Aguaded. Consumo informativo y competencias digitales de estudiantes de periodismo de Colombia, Perú y Venezuela

\section{Competencias comunicativas para la infodieta}

Indagando sobre las habilidades y actitudes de los estudiantes de periodismo frente a los medios y las formas de adquirir el conocimiento sobre el consumo informativo responsable de sus contenidos, a la pregunta referente a de qué manera deberían obtenerse las competencias y habilidades para aprender a informarse, el $81,3 \%$ manifiesta que el consumo de los contenidos de los medios de comunicación e internet son como una dieta y que un profesional debería enseñar los correctos hábitos de informarse, mientras que el restante $18,7 \%$ considera que la mejor manera de adquirir competencias comunicativas debe hacerse de manera autodidacta.

$\mathrm{Al}$ respecto, solamente $12,4 \%$ de los sujetos de análisis aseguraron haber tenido en sus etapas de formación alguna asignatura o currículo relacionado con el consumo responsable de los medios de comunicación; el restante $87,6 \%$ sostuvo lo contrario. Es menester señalar que de la muestra que afirmó haber tenido alguna actividad formativa curricular relacionada con temas de competencia mediática (12,4\%), el 62,3\% pertenece al grupo colombiano, seguido por los prospectivos periodistas peruanos con 21,1 , y el $16,6 \%$ de diferencial pertenece a la muestra venezolana.

Sobre aquellos que respondieron no haber tenido actividades académicas formales sobre competencias mediáticas y consumo responsable de los medios e internet $(87,6 \%), 72,3 \%$ aseguró que aprendió a consumirlos de manera autodidacta, $11,2 \%$ respondió que fueron sus familiares quienes coadyuvaron en su proceso de incursión en el consumo informativo, $8 \%$ referió que fueron instruidos por sus amistades y el 8,5\% señaló haber adquirido las competencias por otros no catalogados.

$\mathrm{Al}$ ser cuestionados sobre la etapa en que debería enseñarse el consumo responsable de los medios de comunicación e internet, 32,3\% de los encuestados muestra preferencia por que sea en la etapa de educación primaria, 23,4\% en secundaria (bachillerato, ESO), 21,7\% en la Universidad, y 3,9\% indicó que debe ser una actividad extraordinaria y desvinculada de la educación formal -talleres, cursos, actividades extra cátedra-; mientras, el 18,7\% piensa que no debería enseñarse competencias comunicativas, pues debe hacerse de manera autodidacta.

\section{Discusión y conclusiones}

Son diversas las conclusiones que arroja el presente estudio conforme a las hipótesis planteadas inicialmente. Junto al estado de hiperconexión de los 
estudiantes de Periodismo analizados, se verifica que sus interacciones en internet se realizan en conjunto con otras actividades tales como asistir a clases o participar en una conversación. Asimismo, 9 de cada 10 encuestados aseguraron mantener comunmente más de tres ventanas o aplicaciones abiertas en paralelo, por lo que existe preponderancia a la acción multitarea como caldo de cultivo de la sobresaturación informativa, infoxicación e infobesidad, tal como se extrae de los estudios de Benito-Ruiz (2009), Cornella (2010), Dias (2014), Romero-Rodríguez (2014), Serrano-Puche (2014). En consecuencia, esto genera las condiciones idóneas para la reducción de la barrera de asimilación cognitiva de las actividades principales ejecutadas en el aula o la conversación y/o de la información a la cual acceden a través de la red (Gross, 1964; Shenk, 2003; Speier et al., 1999).

En relación con la frecuencia de uso promedio de la muestra analizada, el consumo por más de cinco horas al día de internet a través de sus dispositivos móviles ponen de manifiesto un exceso de actividad online que podría catalogarse como "hiperconexión", lo cual podría suponer una adicción a la actividad digital y a las redes sociales, tal y como señalaron los trabajos de Shapira et al. (2003), Echeburúa y de Corral (2010), Caldevilla (2010), Lee y Stapinski (2012), Lam et al. (2009), y más novedoso y específico en el caso de estudiantes universitarios en Galicia, de Marín-Díaz et al. (2015).

Asimismo, las dos terceras partes de los encuestados aseveró que sólo lee el extracto o resumen de las informaciones que comparten o comentan en sus redes sociales, actitud que se generaliza aún más en el grupo etario de 16 a 19 años; por lo tanto, se evidencia un estado de incompletitud en los hábitos de consumo informativo y un incorrecto filtrado de las informaciones que se consumen y divulgan, por eso se evidencia con meridiana claridad que la sobresaturación informativa alcanza el límite real de habilidad cognitiva (Stewart et al., 1992: 131; Pariser, 2011; Doval, 2012; Rainie y Wellman, 2012; Serrano-Puche, 2014), con el posterior efecto desinformativo (Aguaded y Romero-Rodríguez, 2015).

Respecto a la calidad de la información a la que suelen acceder, con meridiana claridad se manifiesta una preeminencia receptiva de contenidos pseudoinformativos, los cuales en su mayoría son listados o videos virales. Mientras que en lo correspondiente a la preferencia de contenidos, los jovenes analizados muestran predilección por temáticas no asociadas con su carrera o futuro profesional, siendo sus factores con mayor interés temas de farándula o informaciones triviales. Se ha detectado igualmente en el presente estudio la relevancia de las variables de edad respecto a los hábitos de consumo informativo, siendo el grupo etario más joven (16-19) el más pro- 
penso a recibir y compartir pseudoinformación, situación que se reduce en los encuestados de mayor edad.

En cuanto a las competencias mediáticas para la formación de hábitos de consumo responsable o infodieta, ocho de cada diez encuestados consideran que deben existir actividades educativas sobre el correcto uso de los contenidos de las redes, aun cuando en su mayoría asegura haber obtenido sus competencias de manera autodidacta en el uso de internet y las redes sociales. Sin embargo, las opiniones acerca de en qué etapa formativa debe enseñarse el correcto consumo de los medios e internet, quedaban repartidas entre educación primaria $(32,3 \%)$, secundaria $(23,4 \%)$ y universitaria $(21,7 \%)$.

Estos resultados destacan que efectivamente existe una tendencia a la desinformación estructural por sobreestimulación receptiva (RomeroRodríguez, 2014), que se debe mayoritariamente a fallos en los refuerzos en materia de competencias digitales y educomunicación a edad temprana (Aguaded y Romero-Rodríguez, 2015). Asimismo, los hábitos de consumo informativo y de interacción son propicios para que los contenidos de irrelevante importancia sean consumidos e incluso compartidos sin un correcto filtrado. De allí parte una imperiosa necesidad de atacar la obesidad informativa con la práctica de dietas digitales que se enfoquen en la cantidad de informaciones consumidas, la capacidad analítica y crítica frente a los mensajes recibidos, la eliminación de conductas multitareas que tienden a la distracción no volitiva y el reentrenamiento en materia de interacciones en las redes sociales.

A raíz de todos estos datos cabe preguntarse si realmente la formación en periodismo está previniendo a los prospectivos periodistas de los efectos negativos del uso excesivo de internet y sus plataformas o si, por el contrario, es necesaria la formación temprana en materia de competencias digitales, informacionales y mediáticas como requisito indispensable para el acceso a esta carrera profesional. En todo caso, debe ser la formación en materia de educomunicación donde reside la responsabilidad formativa de los usos responsables de medios digitales y redes sociales, sobre todo en un escenario y un ecosistema digital tan dinámico como el que caracteriza esta construcción de posmodernidad.

\section{Bibliografía}

Aguaded, Ignacio y Yamile Sandoval (2011), "El televidente, la familia y la escuela ante la recepción participativa de los medios", en V. Tomé y Menesez [eds.], Educaçao e media: da teoria ao terreno, Catelo Branco: RVJ Editores. 
Aguaded, Ignacio y Luis Romero-Rodríguez (2015), "Mediamorfosis y desinformación en la infoesfera: Alfabetización mediática, digital e informacional ante los cambios de hábitos de consumo informativo", en Education in the Knowledge Society, vol. 16, núm. 1, Salamanca, España.

Andrejevic, Mark (2013), Infoglut: How Too Much Information Is Changing the Way We Think and Know, London: Routledge.

Benito-Ruiz, Elena (2009), "Infoxication 2.0”, en M. Thomas [ed.], en Handbook of Research on Web 2.0 and Second Language Learning, Pennsylvania: IGO-InfoSci.

Bray, David (2008), "Information Pollution, Knowledge Overload, Limited Atention Spans and Our Reponsabilities as IS Professionals", en Global Information Technology Management Association (GITMA) World Conference, Atlanta, USA.

Cabalin, Cristian (2014), "Estudiantes conectados y movilizados: El uso de Facebook en las protestas estudiantiles en Chile” en Comunicar, vol. 43, núm. 22 (DOI: http://doi. org/7r7).

Caldevilla, David (2010), "Las redes sociales. Tipologías, uso y consumo de las redes 2.0 en la sociedad digital actual”, en Documentos de las Ciencias de la Información, vol. 33, Madrid, España.

Castells, Manuel (2012), Networks of Outrage and Hope. Social Movements in the Internet Age, Cambridge, MA: Polity Press.

Cornella, Alfons (2010), Infoxicación: Buscando un orden en la información, Barcelona: Infonomia.

Corrin, Linda et al. (2010), “Technological diversity: An investigation of student's technology use in everyday life and academic study, en Learning Media and Technology, vol. 35, núm. 4, Oxford, UK.

Cortés, Carlos (2006), "La fluidez de la información en la era digital”, en Chasqui, núm. 93, Quito, Ecuador.

Crenshaw, Dave (2008), The Myth of Multitasking: How "Doing It All" Gets Nothing Done, San Francisco: Jossey-Bass.

Dias, Patricia (2014), “From 'infoxication' to 'infosaturation': a theoretical overview of the cognitive and social effects of digital immersion”, en Ambitos: Revista Internacional de Comunicación, núm. 24, Sevilla, España.

Díaz-de-Rada, Vidal (2012), "Ventajas e inconvenientes de la encuesta por Internet”, en Papers: Revista de Sociología, vol. 97, núm. 1, Barcelona, España.

Eco, Umberto (1964), Apocalittici e integrati: comunicazioni di massa e teorie della cultura di massa, Milano: Bompiani.

Gallardo, Eliana (2012), "Hablemos de estudiantes digitales y no de nativos digitales”, en UT. Revista de Ciències de l'Educació, núm. 1, Tarragona, España.

García, Antonio, López-de-Ayala, María y Beatriz García (2013), "Hábitos de uso en Internet y en las redes sociales de los adolescentes españoles”, en Comunicar, 41 (DOI: http://doi.org/tj7)

Gisbert, Mercé y Francesc Esteve (2011), “Digital Leaners: La competencia digital de los estudiantes universitarios”, en La cuestión universitaria, vol. 7, Madrid, España. 
Luis M. Romero-Rodríguez e Ignacio Aguaded. Consumo informativo y competencias digitales de estudiantes de periodismo de Colombia, Perú y Venezuela

Gitlin, Todd (2005), Enfermos de información: de cómo el torrente mediático está saturando nuestras vidas, Barcelona: Paidós.

Gleick, James (2011), The Information: A History, A Theory, A Flood, London: Harper Collins.

Gross, Bertram (1964), The Managing of Organizations (Vol. 1), Glencoe: Free Press of Glencoe.

Herrera, Linda (2012), "Youth and Citizenship in the Digital Age: A View from Egypt", en Harvard Educational Review, vol. 82, núm. 3, Boston, USA.

Howe, Neil y William Strauss (1991), Millennials Rising: The Next Great Generation, New York: Vintage Original.

Hurst, Mark (2007), Bit Literacy: Productivity in the Age of Information and E-mail Overload, New York: Good Experience.

Jacoby, Jacob (1977), “Information Load and Decision Quality: Some Contested Issues”, en Journal of Marketing Research, núm. 14, Chicago, USA.

Jacoby, Jacob (1984), "Perspectives on Information Overload", en Journal of Consumer Research, vol. 10, núm. 4, Chicago, USA.

Jacoby, Jacob, Speller, Donald y Carol Kohn (1974), "Brand Choice Behavior As a Function of Information Load: Study II”, en S. Ward, P. Wright y A. Arbor [eds.], Advances in Consumer Research, vol. 1, Minnesotta: Association for Consumer Research.

Johnson, Clay (2012), The Information Diet: A Case for Conscious Consumption, Cambridge: O’Reilly Media.

Klingberg, Torkel (2009), The Overflowing Brain: Information Overload and the Limits of Working Memory, Oxford: Oxford University Press.

Lam, Lawrence et al. (2009), "Factors Associated with Internet Addiction among Adolescents”, en CyberPsychology \& Behavior, vol. 12, núm. 5, New York, USA (DOI: http://doi.org/dcws68).

Lancaster, Lucy y David Stillman (2002), When generations collide. Who they are. Why they clash. How to solve the generation puzzle at work, New York: Collins Business.

Lee, Blanca y Lexine Stapinski (2012), "Seeking Safety on the Internet: Relationship between Social Anxiety and Problematic Internet Use Related”, en Journal of Anxiety Disorders, vol. 26, Saskatchewan, Canada (DOI: http://doi.org/bfzrsg).

Livingstone, Sonia (2008), “Taking Risky Opportunities in Youthful Content Creation: Teenagers' Use of Social Networking Sites for Intimacy, Privacy and Self-expression”, en New Media \& Society, vol. 10, núm. 3, Chicago, USA (DOI: http://doi.org/btc7kw).

Livingstone, Sonia y David Brake (2010), "On the Rapid Rise of Social Networking Sites: New Findings and Policy Implications”, en Children \& Society, vol. 24, núm. 1, London, UK (DOI: http://doi.org/czxgjs).

Livingstone, Sonia et al. (2011), Risks and Safety on the Internet: The Perspective of European Children, London: EU Kids Online.

Livingstone, Sonia y Ellen Helsper (2010), “Balancing Opportunities and Risks in Teenegers' Use of the Internet: the Role of Online Skills and Internet self-efficacy”, en New Media ఓ Society, vol. 12, núm. 2, Chicago, USA (DOI: http://doi.org/fvgp33). 
Convergencia Revista de Ciencias Sociales, núm. 70, 2016, Universidad Autónoma del Estado de México

Lucchetti, Stefania (2010), The Principle of Relevance. The Essential Strategy to Navigate Through the Information Age, Hong Kong: RT Publishing.

Marín-Díaz, Verónica, Sampedro-Requena, Begoña y Juan Muñoz-González (2015), “¿Son adictos a las redes sociales los estudiantes universitarios?, en Revista Complutense de Educación, vol. 26, Madrid, España (DOI: http://doi.org/7sg).

Martin, Carolyn y Bruce Tulgan (2002), Managing the generational mix, Amherst: HRD Press.

Milgram, Stanley (2010), The Individual in a Social World: Essays and Experiments, Londres: Printer\&Martin.

Morduchowicz, Roxana (2008), La generación Multimedia. Significados, consumos y prácticas culturales de los jóvenes, Buenos Aires: Paidós.

Nielsen (2014), Nielsen World Internet Stats, New York: Nielsen.

Niada, Marco (2010), Il tempo breve. Nell'era della frenesia: la fine della memoria e la morte dell'attenzione, Milano: Garzanti.

Oblinger, Diana y James Oblinger (2005), Educating the net generation, Washington: Educause.

Pariser, Eli (2011), The Filter Bubble: What The Internet Is Hiding From You, New York: The Penguin Press.

Prensky, Marc (2001), The digital game-based learning revolution. Digital Game-Based Learning Revolution, New York: McGraw-Hill.

Rainie, Lee y Barry Wellman (2012), Networked. The New Social Operating System, Cambridge: The MIT Press.

Reig, Dolors y Luis F. Vílchez (2013), Los jóvenes en la era de la hiperconectividad: tendencias, claves y miradas, Madrid: Fundación Telefónica.

Rial, Antonio et al. (2014), "Actitudes, percepciones y usos de Internet y las redes sociales entre los adolescentes de la comunidad gallega (España)", en Anales de Psicología, vol. 30, núm. 2, Murcia, España (DOI: http://doi.org/7sf).

Rodríguez, Delia (2013), Memecracia. Los virales que nos gobiernan, Barcelona: Gestión 2000.

Romero-Rodríguez, Luis (2012), "La desinformación en la nueva aldea global", en Comunicación, núm. 159-160, Caracas, Venezuela.

Romero-Rodríguez, Luis (2014), Pragmática de la desinformación: Estratagemas e incidencia de la calidad informativa de los medios (Tesis doctoral), Huelva: Universidad de Huelva.

Rosen, Larry et al. (2010), Rewired: Understanding the i-generation and the way they learn, Hampshire: Palgrave Macmillan.

Sabada, Charo y Xavier Bringué (2009), "Niños y adolescentes españoles ante las pantallas: rasgos configuradores de una generación interactiva”, en CEE Participación Educativa, núm. 15, Madrid, España.

Sandoval, Yamile e Ignacio Aguaded (2012), "Nuevas audiencias, nuevas responsabilidades. La competencia mediática en la era de la convergencia”, en Icono 14, vol. 10, núm. 3, Madrid, España. 
Luis M. Romero-Rodríguez e Ignacio Aguaded. Consumo informativo y competencias digitales de estudiantes de periodismo de Colombia, Perú y Venezuela

Serrano-Puche, Javier (2014), "Por una dieta digital: hábitos mediáticos saludables contra la 'obesidad informativa ", en Ámbitos, núm. 24, Sevilla, España.

Shapira, Nathan et al. (2003), "Problematic Internet Use: Proposed Classification and Diagnostic Criteria”, en Depression and Anxiety, vol. 17, Maryland, USA (DOI: http://doi.org/b2xq47).

Shenk, David (2003), “Concept of Information Overload”, en E-Science, Encyclopedia of International Media and Communications, 2, Boston: Elsevier.

Speier, Cheri et al. (1999), "The Influence of Task Interruption on Individual Decision Making: An Information Overload Perspective”, en Decision Science, 1999, vol. 30, núm. 2, Chicago, USA.

Stewart, Tom et al. (1992), "Effects of Improved Information on the Components of Skill in Weather Forecasting", en Organizational Behavior and Human Decision Processes, núm. 53, Seattle, USA (DOI: http://doi.org/bdmhd5).

Tapscott, Don (2009), Growing up digital: The rise of the net generation, New York: McGraw-Hill.

Toffler, Alvin (1970), Future Shock, Nueva York: Bantam Books.

Valcke, Martin et al. (2011), "Long-term Study of Safe Internet Use of Young Children”, en Computers \& Education, núm. 57, Taipei, Taiwan (DOI: http://doi.org/b58wjd).

\section{Recursos electrónicos}

Doval, Montse (2012, 10 de abril), "Por una dieta informativa más variada y sana", en Aceprensa. Disponible en: http://goo.gl/vHq3D6 [26 de octubre de 2014].

Echeburúa, Enrique y Paz de Corral (2010), “Adicción a las nuevas tecnologías y a las redes sociales en jóvenes: un nuevo reto”, en Adicciones, 22. Disponible en: http://goo.gl/ jZe0x3 [15 de diciembre de 2011].

Instituto Nacional de Estadística de España (INE) (2013), Encuesta sobre equipamiento y uso de tecnologias de comunicación e información en los hogares. Disponible en: http://www. ine.es [26 de octubre de 2014].

Internet World Stats (2012), Internet Usage Statistics for all the Americas. Disponible en: http://goo.gl/CwWjCc [6 de agosto de 2014].

Pew Research Center (2014), Social Networking Fact Sheet. Disponible en: http://goo.gl/ WfL4PR [18 de septiembre de 2015].

White, Davis (2010), “Transcripción del video 'visitors and residents”, en TALL blog Online education with the University of Oxford. Disponible en: http://goo.gl/YAUAB2 [2 de octubre de 2014]. 





Luis M. Romero-Rodríguez e Ignacio Aguaded. Consumo informativo y competencias digitales de estudiantes de periodismo de Colombia, Perú y Venezuela

\section{Tabla 2}

Tipología de contenidos recibidos por grupo etario

\begin{tabular}{ccccc}
\hline $\begin{array}{c}\text { Grupo } \\
\text { etario / } \\
\text { Contenido }\end{array}$ & $\begin{array}{c}\text { Listadose } \\
\text { información } \\
\text { viral }\end{array}$ & $\begin{array}{c}\text { Videos } \\
\text { musicales y } \\
\text { virales }\end{array}$ & $\begin{array}{c}\text { Noticias e } \\
\text { información útil }\end{array}$ & $\begin{array}{c}\text { Frases célebres y } \\
\text { otros contenidos }\end{array}$ \\
\hline $16-19$ & $72,2 \%$ & $11,2 \%$ & $9,5 \%$ & $7,1 \%$ \\
\hline $20-23$ & $67,1 \%$ & $26,1 \%$ & $3,7 \%$ & $3,1 \%$ \\
\hline $24-27$ & $51,3 \%$ & $29 \%$ & $10,3 \%$ & $9,4 \%$ \\
\hline+28 & $44,1 \%$ & $18,3 \%$ & $30 \%$ & $7,6 \%$ \\
\hline Total & $58,6 \%$ & $21,1 \%$ & $13,4 \%$ & $6,9 \%$ \\
\hline
\end{tabular}

Fuente: Elaboración propia.

Tabla 3

Pruebas de Chi-Cuadrado

\begin{tabular}{lrcc}
\hline & Valor & gl & $\begin{array}{c}\text { Sig. asintótica } \\
\text { (bilateral) }\end{array}$ \\
\hline Chi-cuadrado de Pearson & $83,948(\mathrm{a})$ & 9 &, 000 \\
\hline Razón de verosimilitudes & 68,901 & 9 &, 000 \\
\hline Asociación lineal por lineal & 2,003 & 1 &, 157 \\
\hline N de casos válidos & 1603 & & \\
\hline
\end{tabular}

Nota: (a) 4 casillas $(25,0 \%)$ tienen una frecuencia esperada inferior a 5. La frecuencia mínima esperada es 1,03 .

Fuente: Elaboración propia. 
Figura 1

Tipología de contenidos recibidos por grupo etario

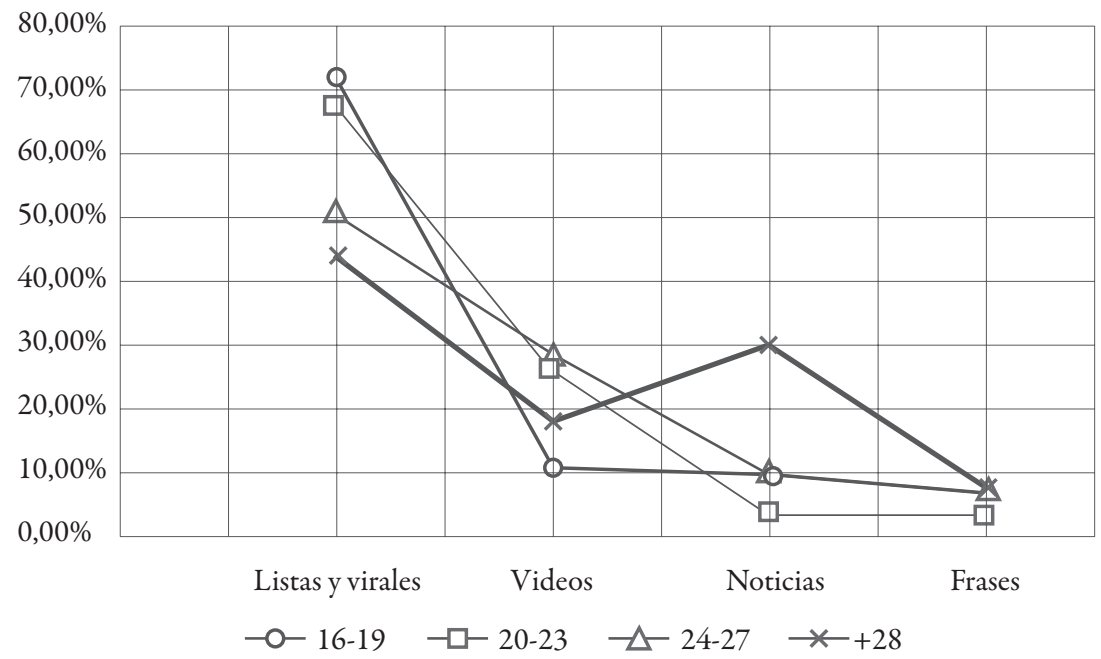

Fuente: Elaboración propia.

Luis M. Romero Rodríguez. Doctor en Comunicación. Es coordinador de Comunicaciones e investigador en Alfamed: Red Interuniversitaria Euroamericana de Investigación sobre Competencias Mediáticas para la Ciudadanía y profesor invitado de la Facultad de Ciencias de la Educación de la Universidad de Huelva (España). Líneas de investigación: desinformación, infoxicación, educomunicación (media literacy) y competencias mediáticas. Publicaciones recientes: "Mediamorfosis y desinformación en la infoesfera: Alfabetización mediática, digital e informacional ante los cambios de hábitos de consumo informativo", en Education in the Knowledge Society, 16(1), Salamanca: EKS (2015); Pragmática de la desinformación: Estratagemas e incidencia de la calidad informativa de los medios, Huelva: Repositorio Institucional Arias Montano (2014); "Hacia un estado de la cuestión de las investigaciones sobre desinformación / misinformación”, en Correspondencia \& Análisis, núm. 3, Lima: USMP (2013).

Ignacio Aguaded. Doctor en Psicopedagogía. Es catedrático de la Facultad de Ciencias de la Educación de la Universidad de Huelva, España. Líneas de investigación: educomunicación (media literacy) y competencias mediá- 
ticas. Publicaciones recientes: "La ciudad, espacio de educomunicación y participación de la ciudadanía alfabetizada", en Revista Latinoamericana de Ciencias de la Comunicación, núm. 16, Sao Paulo: Universidade de Sao Paulo (2014); "Desarrollo y evolución de la plataforma MiriadaX", en Actas III Workshops Internacional sobre Creaciones de MOOC, Málaga: UMA (2014); "Experiencias de posgrado sobre computación en la red (cloud computing) con software social", en Estudios sobre Educación, vol. 27, Navarra: UNAV (2014).

Recepción: 28 de febrero de 2015.

Aprobación: 22 de septiembre de 2015. 
